\title{
O Efeito de Substratos Orgânicos no Crescimento Inicial de Pitaya Vermelha Cultivada em Campo Grande, Mato Grosso do Sul
}

\section{The Effect of Organic Fertilization on the Initial Development of red Pitaya Grown in Campo Grande, Mato Grosso do Sul}

\author{
Pâmella Gonçalves da Silva*a; Rosemary Matias ${ }^{\mathrm{a}}$; Ademir Kleber Morbeck de Oliveira ${ }^{\mathrm{a}}$ \\ ${ }^{a}$ Universidade Anhanguera Uniderp, Programa de Pós-Graduação Stricto Sensu em Meio Ambiente e Desenvolvimento Regional. MS, Brasil. \\ *E-mail: pamellasdepp@hotmail.com
}

\begin{abstract}
Resumo
O cultivo da pitaya (Hylocereus spp) foi introduzido, no Brasil, na década de 1990. No Estado de Mato Grosso do Sul, uma das espécies exploradas, dentro deste gênero, por produtores da agricultura familiar, é a Hylocereus polyrhizus (Weber) Britton \& Rose. Apesar do crescimento da área cultivada existem poucas informações sobre as melhores condições para o cultivo das plantas, o que dificulta maiores ganhos em produtividade. Por este motivo, justifica-se investigar o uso de substratos para avaliar o crescimento inicial da pitaya, tais como: os orgânicos. Levando-se em consideração a importância da espécie para a agricultura familiar, objetivou-se avaliar o crescimento inicial de Hylocereus polyrhizus em diferentes substratos, enriquecidos com materiais de origem orgânica. O delineamento experimental foi o inteiramente casualizado em esquema fatorial $5 \times 4$ ( 5 tratamentos $\times 4$ repetições), em que a espécie foi cultivada frente a três adubos orgânicos e duas testemunhas, durante 360 dias. Os tratamentos foram: T1 - testemunha (100\% solo arenoso), T2 - testemunha (NPK), T3 - $90 \%$ solo arenoso $+10 \%$ de cama de frango, $\mathrm{T} 4-80 \%$ solo arenoso $+20 \%$ esterco bovino e, $\mathrm{T} 5-80 \%$ solo arenoso $+20 \%$ esterco ovino. Os resultados de crescimento inicial foram analisados aos 360 dias. A pitaya, quando em solos arenosos, cresce, floresce a frutifica mais rapidamente na condição do tratamento 4 ( $80 \%$ solo $+20 \%$ esterco bovino $)$.
\end{abstract}

Palavras-chave: Desenvolvimento. Ambiente e Sustentabilidade. Hylocereus spp. Adubação Orgânica. Crescimento Inicial.

\begin{abstract}
The pitaya cultivation (Hylocereus spp) was introduced in Brazil in the 1990s. In the State of Mato Grosso do Sul, one of the species explored, within this genus, by family farmers, is Hylocereus polyrhizus (Weber) Britton \& Rose. Despite the growth of the cultivated area, there is little information on the best conditions for the plants cultivation, which hinders greater gains in productivity. For this reason, it is justified to investigate the use of substrates to evaluate the pitaya initial growth, such as organic ones. Taking into account the importance of the species for family farming, the objective was to evaluate the initial growth of Hylocereus polyrhizus on different substrates, enriched with materials of organic origin. The experimental design was completely randomized in a $5 \mathrm{x} 4$ factorial scheme ( 5 treatments $\mathrm{x} 4$ repetitions), where the species was grown before three organic fertilizers and two controls, for 360 days. The treatments were: T1 - control (100\% sandy soil), T2 - control (NPK), T3 - 90\% sandy soil $+10 \%$ chicken manure, T4 - 80\% sandy soil $+20 \%$ bovine manure and, T5 - $80 \%$ sandy soil $+20 \%$ sheep manure. The results of initial growth were analyzed at 360 days. Pitaya, when in sandy soils, grows, blooms and bears fruit faster under treatment 4 ( $80 \%$ soil $+20 \%$ bovine manure) .
\end{abstract}

Keywords: Development. Environment and Sustainability; Hylocereus spp. Organic Fertilization. Initial Growth.

\section{Introdução}

As espécies vegetais exóticas são introduzidas, por ação humana, em determinadas regiões, de forma intencional ou acidental, e podem se tornar importantes fontes de renda para os agricultores. Alguns exemplos de espécies exóticas frutíferas, exploradas economicamente no Brasil, são: a bananeira (Musa paradisiaca L.), o coqueiro (Cocos nucifera L.), a laranjeira (Citrus sinensis (L.) Osbeck.), a macieira (Malus domestica Borkh.), entre outras (ROGEZ et al., 2004; SCHWARTZ et al., 2006).

Outra espécie exótica, que também tem importância na dieta da população e que vem despertando o interesse dos produtores nacionais é a pitaya (Cactaceae), também conhecida como "Fruta-do-Dragão". Uma planta considerada rústica, que tem como centro de origem, regiões da América do Norte (México), Central e do Sul (FREITAS; MITCHAM,
2013). Sua distribuição está concentrada nas regiões tropicais, subtropicais e asiáticas (GUNASENA et al., 2007; XU et al., 2016), normalmente se desenvolvendo bem em regiões tropicais.

Atualmente, três grupos de pitaya se destacam em função de seu valor comercial: a pitaya com casca vermelha e polpa branca (Hylocereus undatus (Haw.) Britton \& Rose); a com casca e polpa vermelha (Hylocereus polyrhizus (Weber) Britton \& Rose) e; a com casca amarela, com espinhos e polpa branca (Hylocereus megalanthus (K. Schumann ex Vaupel) Ralf Bauer).

Todas essas espécies de pitaya são epífitas (necessitam de outras plantas ou estruturas para se manterem eretas) e possuem floração lateral branca, abrindo ao anoitecer e exalando um perfume adocicado, que atrai as mariposas, seus polinizadores (DONADIO, 2009). Seus frutos podem ser 
consumidos in natura ou processados, na forma de sorvetes, geleias, sucos, vinhos e saladas, sendo ricos em vitaminas B1, B2, B3, E e C, além de betacarotenos, licopenos, carboidratos, sais (potássio e magnésio) e polifenóis (ABREU et al., 2012).

Quanto às características químicas dos frutos, além do valor nutricional, pode-se destacar, suas propriedades bioativas (HOR et al., 2012) decorrentes dos elevados teores de compostos com capacidade antioxidante, fator atribuído aos polifenóis e vitamina C (DEMBITSKY et al., 2011). Por estes motivos, além da beleza dos frutos e seu sabor, suas características nutricionais permitem sua venda por um alto valor, propiciando renda aos agricultores familiares (WANITCHANG et al., 2010). Enquanto, nas sementes, são encontrados cerca de $50 \%$ de ácidos graxos essenciais, sendo $48 \%$ de ácido linoleico e 1,5\% de ácido linolênico (ABREU et al., 2012).

Apesar de seu potencial de uso, no Brasil, seu cultivo ainda é recente, com áreas de produção encontradas, principalmente, nos Estados de São Paulo, região de Catanduva (BASTOS et al., 2006) e, em Minas Gerais, região de Lavras (MARQUES et al., 2011). Em Mato Grosso do Sul, o cultivo foi introduzindo recentemente, com registro de plantações em Dourados e Campo Grande, em pequena escala (MS RURAL, 2019). Entretanto, indicações preliminares demonstram sua rápida adaptação a determinadas regiões do Estado, o que permitiu seu cultivo, pelos agricultores familiares.

Porém, o aumento da área de cultivo tem gerado problemas relacionados com a falta de conhecimento sobre as melhores condições para seu plantio, pois não existem informações sobre os tratos culturais adequados, principalmente, em relação aos diferentes solos encontrados no Estado, além de indicações sobre seu crescimento em diferentes condições de substratos.

Os substratos orgânicos desempenham a função de prover nutrientes e aumentar a produtividade das plantas (MINAMI, 2000), bem como ampliar a capacidade de retenção de água, disponibilizando-a por mais tempo (HOFFMANN et al., 2001; SOUTO et al., 2005). Além disto, contribuem para a aeração do substrato, auxiliando no desenvolvimento das raízes e, consequentemente, no equilíbrio dinâmico no sistema água-solo-planta-atmosfera (CUNHA et al., 2006). As características descritas acima evidenciam as vantagens do emprego de substratos orgânicos no campo, aliadas a todos os seus benefícios, está o baixo custo, outro ponto de significativa importância para o pequeno produtor.

Dessa maneira, objetivou-se avaliar o crescimento inicial da espécie Hylocereus polyrhizus em solo arenoso, enriquecido com diferentes proporções de materiais orgânicos, por 360 dias.

\section{Desenvolvimento}

\subsection{Revisão bibliográfica}

A família Cactaceae apresenta 124 gêneros, contando com aproximadamente 1.440 espécies, distribuídas, quase em sua totalidade, na faixa neotropical (HUNT et al., 2006), sendo que, no Brasil, a família está representada por 37 gêneros (CALVENTE, 2010). Suas espécies são conhecidas por apresentarem especializações de caráter anatômico, morfológico e funcional e, em função destes aspectos tem como característica a rápida absorção, grande retenção e mínimo consumo de água, captada do solo ou diretamente do ar. Suas adaptações, como a presença de espinhos, que são folhas transformadas, propiciam a economia de água em ambientes áridos, nos quais a presença de chuva é estacional ou rara (RIZZINI, 1987).

Em geral, são espécies xerófitas, suculentas, perenes e adaptadas às regiões semiáridas ou áridas, possuindo inúmeros hábitos, sendo os mais comuns: arbóreo, arbustivo, subarbustivo, trepador, epífito ou geófito (ZAPPI; TAYLOR, 2008).

Por sua robustez e, muitas vezes, produção de frutos de características exóticas, seu cultivo tem ganhando espaço em muitas regiões, como no Brasil. Um dos exemplares, que vem se destacando no território nacional é a pitaya (Hylocereus spp.). Os nomes populares pitaya e pitahaya tiveram sua origem a partir do idioma taíno, que pertence à família linguística arahuaca, que significa "fruta escamosa", utilizado no México. Esses nomes são utilizados para definirem gêneros distintos (Pitayas - cactáceas colunares dos gêneros Stenocereus e Cereus e; Pitahayas - cactáceas epífitas dos gêneros Hylocereus e Selenicereus) e são comumente utilizados na América Central e do Sul (ORTIZHERNÁNDEZ, 1999; RODRÍGUEZ CANTO, 2000).

Segundo Ortiz-Hernández e Carrillo-Salazar (2012), o gênero Hylocereus possui 14 espécies, encontradas, majoritariamente, em regiões subtropicais e tropicais de florestas, além de zonas áridas. Entre as espécies cultivadas, atualmente, três se destacam, sendo: $H$. undatus, $H$. polyrhizus e H. megalanthus (Figura 1), apresentando grande produção de frutos, que podem ser consumidos in natura ou utilizados como matéria-prima na indústria de alimentos.

Figura 1 - Frutos oriundos das três principais espécies de pitaya: Hylocereus undatus (A), Hylocereus polyrhizus (B) e Hylocereus megalanthus (C)
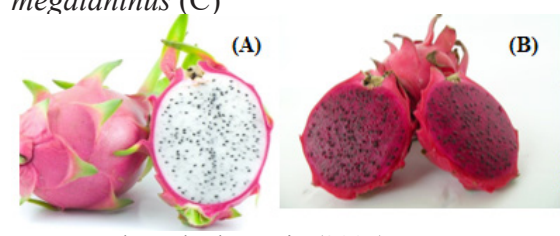

(B)

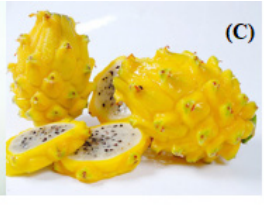

Fonte: Adaptado de Zanin (2007)

A palavra pitaya teve seu primeiro registro datado em 1494, por Pedro Mártir de Anglería, um historiador do descobrimento das Américas, que relatou: "Hay otro árbol que nace en las hendeduras de las piedras, no en buen suelo; se llama pytahaya". Sua primeira representação, em forma de desenho, data de 1535, feita por Gonzalo Fernández de 
Oviedo y Valdés, um colonizador espanhol, em seu relato ao rei Carlos I (Figura 2) em "Historia general y natural de las Indias, islas y tierra firme del mar océano" (RODRÍGUEZ CANTO, 2013).

Figura 2 - Primeira representação do fruto de pitaya, em forma de ilustração, feita por Gonzalo Fernández de Oviedo y Valdés em 1535

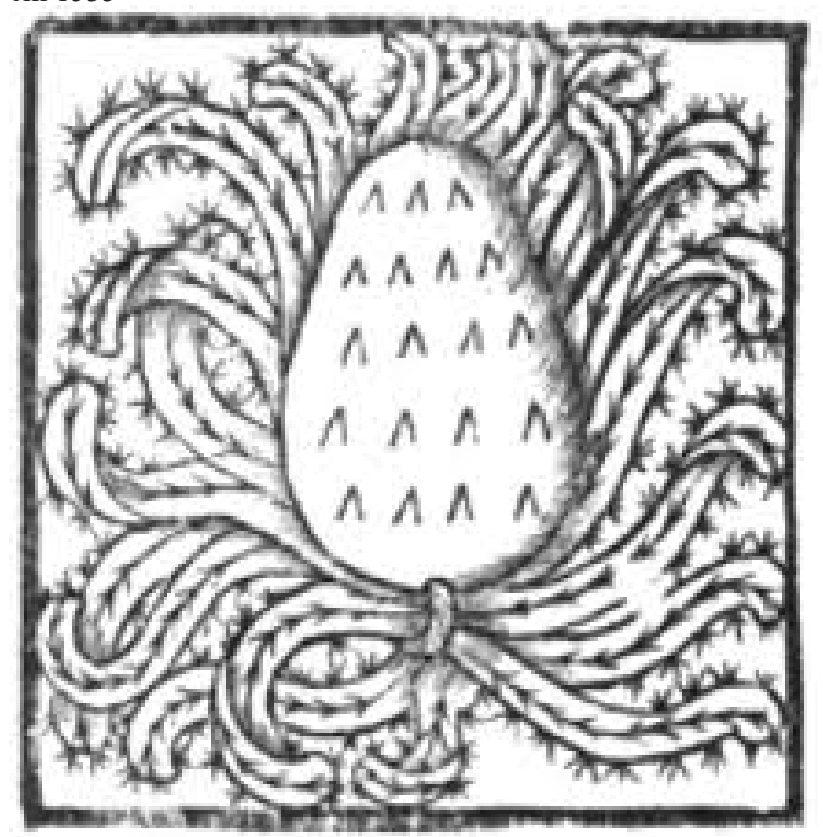

Fonte: Krapovickas (2010).

Hylocereus spp. é uma espécie vegetal epífita, rupícola ou terrestre ramificada, com ramos trígonos, ou trialados, com pouco mais de $20 \mathrm{~cm}$ (em média de comprimento) e 5 a 7 $\mathrm{cm}$ de diâmetro. Suas asas possuem $2,3 \mathrm{~cm}$ de altura, de cor verde ou grisácea (quando envelhecem), em função da cera que a recobre, com bordos agudos, crenados e córneos. Nos talos existem aréolas de 2 a $3 \mathrm{~cm}$ de diâmetro, distantes de 3 a $5 \mathrm{~cm}$ entre si, com espinhos de 3 a 6 cada uma ( 1 a $4 \mathrm{~mm}$ de comprimento) e, subaladas com base dilatada em um bulbo (CANTO, 1993).

As flores são laterais, de antese noturna, com 20 a $35 \mathrm{~cm}$ de comprimento, brancas, completas, perfumadas ao abrir à noite, quando são polinizadas por insetos, principalmente, as mariposas. A flor contém numerosos estames, acima de 800 em uma só, arranjados em duas fileiras, ao redor do pistilo, que é formado por 14 a 28 estiletes de cor creme. As sépalas são de cor verde-clara. O pólen é abundante e de cor amarela. As raízes são fibrosas e abundantes, podendo ocorrer, ainda, numerosas raízes adventícias (CANTO, 1993).

Seus frutos possuem diversas cores, como: vermelho, amarelo e roxo, o que os torna atrativos ao consumidor. Sua polpa pode apresentar coloração esbranquiçada ou avermelhada, com sabor agradável, desde levemente adocicado ao doce, e presença de pequenas sementes de coloração escura (CANTO, 1993).

As flores se desenvolvem nas laterais dos caules modificados, conforme descrito por Marques et al. (2011).
Estes autores observaram as etapas do desenvolvimento fenológico, no período reprodutivo, da espécie Hylocereus polyrhizus, e contribuíram para o conhecimento referente às características morfológicas, tais como: o aparecimento do botão floral e caracterização das flores, sistema reprodutivo, além de descrever o surgimento e maturação do fruto, entre outros eventos (Figura 3).

Figura 3 - Fenologia do período reprodutivo de pitaya vermelha. A - Aparecimento do botão floral; B, C, D, E, F, H e I - alongamento do botão floral; J - início do desprendimento das sépalas; K e L - abertura da flor; M - flor polinizada; N e O - fruto em crescimento; P - início da maturação do fruto; Q - maturação do fruto; R e S - frutos maduros colhidos; e, T - detalhe da aréola cicatrizada após a retirada do fruto

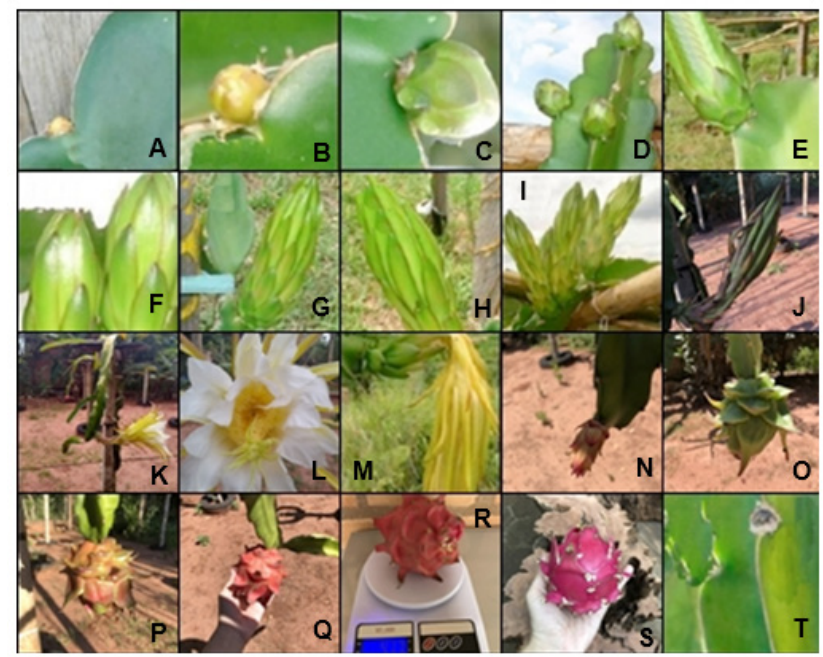

Fonte: Adaptado de Marques et al. (2011).

No Brasil, o início do cultivo da pitaya é recente, sendo iniciado na década de 1990, pela produtora pioneira Anoemisia Sader, em Itajobi - São Paulo. A partir deste momento, o cultivo comercial foi se expandindo para as mais diversas regiões, como por exemplo, Minas Gerais, Paraná, Santa Catarina, Mato Grosso do Sul, Rio Grande do Norte, Ceará e Pernambuco (SILVA, 2011).

Seu cultivo vem se intensificando em função dos preços obtidos pelos frutos, nos mercados regional, nacional e internacional, o que estimulou o desenvolvimento de diversos sistemas de plantio, elevando a produtividade e área cultivada. Atualmente, em países produtores como México, Nicarágua, Malásia, Vietnã, Israel e mesmo no Brasil, a produção de pitaya ocorre, predominantemente, em pequenos cultivos, com comercialização restrita a mercados com maior poder aquisitivo (ESTELLENA, 2011; ORTIZ-HERNÁNDEZ; CARRILLO-SALAZAR, 2012).

Em decorrência do tipo de cultivo e região produtora, sua produtividade média oscila entre 10 a $30 \mathrm{t} \mathrm{ha}^{-1} \mathrm{ano}^{-1}$, função das condições edafoclimáticas, técnicas de cultivo e idade do pomar (LE BELLEC et al., 2006). Os dados obtidos no Censo Agropecuário de 2017 apontaram que, em 2017, o Brasil produziu cerca de 1.493,19 toneladas de pitaya, em 3.086 estabelecimentos agropecuários (IBGE, 2017), evidenciando a crescente demanda e produção da fruta no território nacional. 


\subsection{Experimentos}

O cultivo de Hylocereus polyrhizus foi realizado a campo, pleno Sol, na propriedade Rancho D\&S (20²6'01'S; 54'31'27'O), localizada em Campo Grande, Mato Grosso do Sul, no período de abril de 2019 a abril de 2020. Foram utilizadas 20 mudas de $H$. polyrhizuz (pitaya vermelha) adquiridas de matrizes cultivadas por produtores familiares em Campo Grande (20²4'36.4'’S; 54²3'54.3'O), previamente enraizadas e de mesma idade, com estacas padronizadas em $30 \mathrm{~cm}$ de comprimento.

$\mathrm{O}$ delineamento experimental foi $\mathrm{o}$ inteiramente casualizado, em esquema fatorial $5 \times 4$ (5 tratamentos $\times 4$ repetições), em que a espécie estudada foi cultivada frente a 3 adubos orgânicos (cama de frango, esterco ovino e esterco bovino) e 2 testemunhas (química, com adição de NPK ao solo e, testemunha pura, sem adubação). O solo na área do experimento foi caracterizado como solo arenoso (Neossolo Quartzarênico), no qual as adubações foram incorporadas.

\subsection{Condução do experimento e tratos culturais}

Por se tratar de uma espécie de cactácea epífita, foi realizado o tutoramento das mudas, utilizando-se o modelo de tutoramento em cruzeta. Foram utilizados postes de concreto de, aproximadamente, dois metros de altura, com $40 \mathrm{~cm}$ enterrados no solo e 1,60 m acima do nível do solo. Posteriormente, na parte superior, foi fixada a cruzeta de madeira, bem como uma base de pneu para acomodar a planta após seu crescimento até o ápice do poste, sendo a muda fixada com auxílio de elásticos (Figura 4).

Figura 4 - Tutor de concreto de modelo cruzeta utilizado no cultivo de pitaya, Campo Grande, Mato Grosso do Sul, 2019.

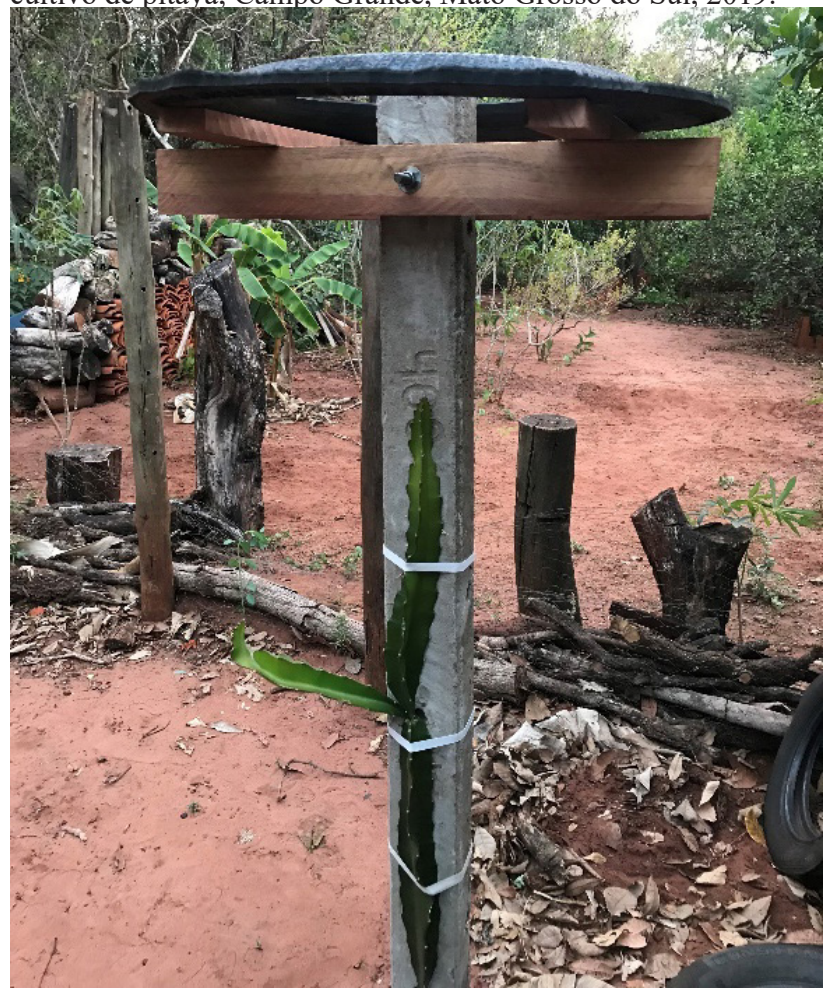

Fonte: os autores.
$\mathrm{Na}$ base do tutor de concreto foi aberta uma cova de dimensões 30x30x30 cm, correspondendo a 34,56 kg de substrato. A partir deste montante foram realizados os cálculos para a incorporação dos substratos, nas seguintes proporções: T1 - testemunha (100\% solo arenoso); T2 - testemunha (NPK: $\mathrm{N}=2,5 \mathrm{~g}$ de ureia; $\mathrm{P}=20 \mathrm{~g}$ de superfosfato simples e, $\mathrm{K}=3,5 \mathrm{~g}$ de cloreto de potássio); T3 - 90\% solo arenoso + $10 \%$ de cama de frango curtida (cada cova recebeu 3,456 kg de substrato); T4 $-80 \%$ solo arenoso $+20 \%$ esterco bovino curtido $(6,912 \mathrm{~kg}$ de esterco por repetição) e; T5 - 80\% solo arenoso $+20 \%$ esterco ovino curtido $(6,912 \mathrm{~kg}$ de esterco por cova).

Os tutores de cada tratamento e repetição foram colocados na distância de 2 metros entre linhas e colunas (Figura 5), para que não houvesse competição entre os indivíduos. A análise de crescimento foi realizada a cada intervalo de 30 dias, após o plantio $(30,60,90,120,150,180,210,240,270,300,330$ e 320 dias), com auxílio de fita métrica $(\mathrm{cm})$, medindo da base do cladódio principal até seu ápice.

Figura 5 - Espaçamento entre linhas e colunas dos tratamentos, cultivo de Hylocereus polyrhizus, Campo Grande, Mato Grosso do Sul, 2019

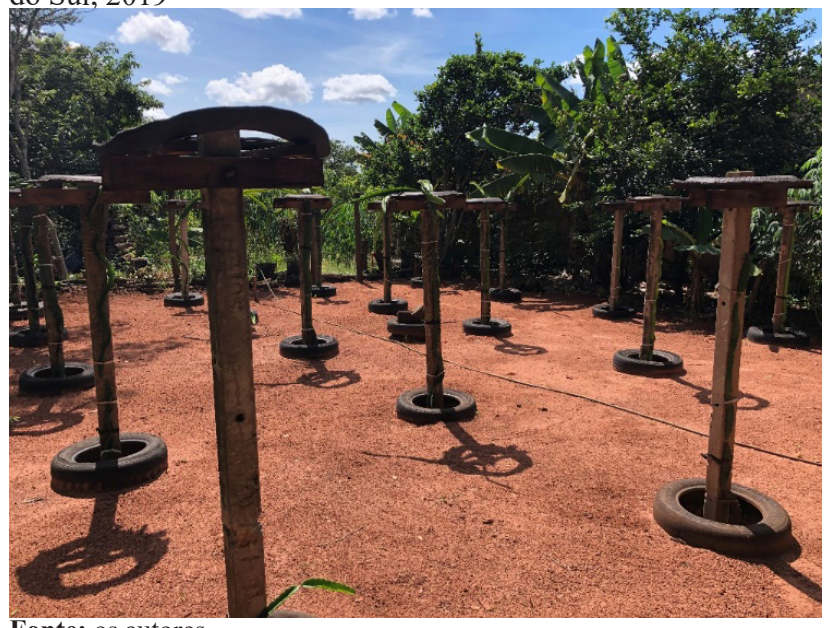

Fonte: os autores.

\subsection{Tratamento estatístico}

Os resultados obtidos foram analisados através de gráficos com curva de regressão, com apresentação do $\mathrm{R}^{2}$. Para análise do melhor desenvolvimento após 360 dias, foram utilizados os dados da última coleta e realizada a análise de variância (ANOVA) e quando ocorreu significância, as médias da variável crescimento inicial foram submetidas ao teste de Tukey a $5 \%(\mathrm{p}<0,05)$ de probabilidade.

\subsection{Resultados e Discussão}

Os resultados apontaram diferenças entre os tratamentos $(\mathrm{DMS}(5 \%)=59,5434 ; \mathrm{DP}=22,158520 ; \mathrm{CV}=9,9306184)$, sendo T3, T4 e T5 iguais e com maior média em altura (Quadro 1). O menor crescimento de plantas foi observado em $\mathrm{T} 1$, demonstrando que solos sem adubação não são adequados para a espécie.

Por outro lado, a adubação orgânica, seja essa com cama 
de frango, esterco bovino e ovino é necessária para propiciar que os indivíduos se desenvolvam melhor, embora cada tipo de material orgânico possua diferentes características químicas.

Quadro 1 - Crescimento de plantas de Hylocereus polyrhizus, cultivadas em diferentes substratos, Campo Grande, Mato Grosso do Sul, 2020

\begin{tabular}{|c|c|}
\hline Tratamentos & $\begin{array}{c}\text { Crescimento } \\
\text { (cm) }\end{array}$ \\
\hline T1 - Testemunha & $132,3 \mathrm{c}$ \\
\hline T2 - NPK & $212 \mathrm{~b}$ \\
\hline T3 - 90\% solo $+10 \%$ de cama de frango & $242,7 \mathrm{ab}$ \\
\hline T4 - 80\% solo $+20 \%$ esterco bovino & $276,7 \mathrm{a}$ \\
\hline T5 $-80 \%$ solo $+20 \%$ esterco ovino & $252 \mathrm{ab}$ \\
\hline
\end{tabular}

*Valores seguidos da mesma letra, na coluna, não diferem estatisticamente pelo teste de Tukey $(\mathrm{p}<0.05)$.

Fonte: dados da pesquisa.

Os adubos utilizados possuem diferentes características física e químicas e, por este motivo, poderiam propiciar um crescimento diferenciado das plantas. Por exemplo, Simplício et al. (2004) descrevem que o esterco ovino apresenta elevados teores de N, P e K, quando comparado a outros adubos orgânicos. Já Pauletti e Motta (2004) descrevem que o esterco bovino fresco apresenta $1,5 \%$ de N, 1,4 \% de $\mathrm{P}_{2} \mathrm{O}_{5}$, $1,5 \%$ de $\mathrm{K}_{2} \mathrm{O}$ e $15 \%$ de matéria seca, além de micronutrientes como Zn, Cu, Fe e Mn. Por outro lado, Kelleher et al. (2002) indicam que a composição da cama de frango, somada aos dejetos, é constituída, predominantemente, de água e carbono, com menores quantidades de $\mathrm{N}$ e $\mathrm{P}$, além de pequena quantidade de $\mathrm{Cl}, \mathrm{Ca}, \mathrm{Mg}, \mathrm{Na}, \mathrm{Mn}, \mathrm{Fe}, \mathrm{Cu}, \mathrm{Zn}$ e As.

Assim, pode-se afirmar que embora suas características sejam distintas, o produtor pode fazer uso de qualquer um, com bons resultados. Entretanto, quando analisadas as curvas de crescimento (Figura 6), o tratamento com esterco bovino apresentou uma curva de crescimento que se destaca, indicando ser o mais adequado para a espécie, nas condições de cultivo. Esse melhor desempenho pode estar relacionado às características particulares de cada tipo de esterco, pois os processos de digestão da matéria orgânica consumida pelos animais, além do tipo de capim, do qual eles se alimentam, alteram as características químicas do material.

Figura 6 - Crescimento de plantas de Hylocereus polyrhizus, cultivadas em diferentes substratos, Campo Grande, Mato Grosso do Sul, 2020

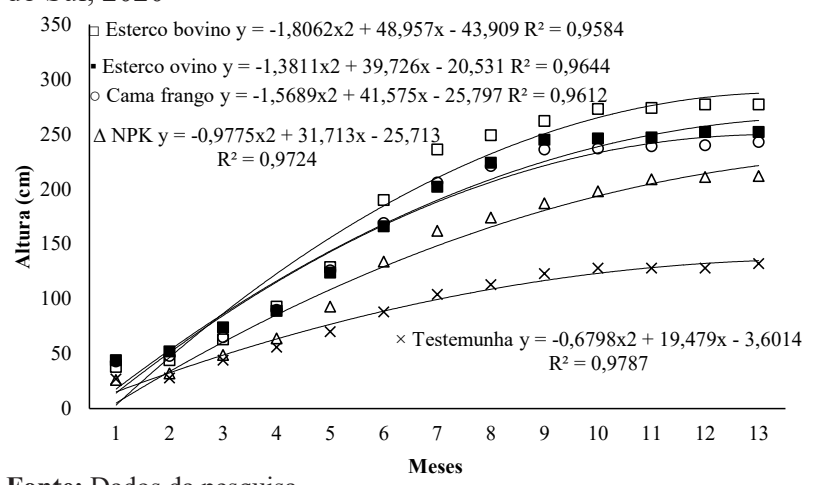

Fonte: Dados da pesquisa.
No geral, as maiores médias de crescimento nos tratamentos com adição de material orgânico (Quadro 1), quando comparadas aos tratamentos testemunha e NPK, demonstram que a utilização de insumos orgânicos alterou as características físicas e químicas do solo, de maneira positiva, propiciando ganhos de crescimento.

De acordo com Andreola et al. (2000) e Oliveira et al. (2009), o esterco propicia uma série de interações benéficas com micro-organismos do solo. Dessa maneira, diminui sua densidade aparente, melhora sua agregação, estrutura e estabilidade, além de aumentar a capacidade de infiltração e retenção de água, aeração e penetração radicular. Além disso, uma parte do esterco é transformado em húmus (mais estável), permitindo a liberação contínua de nutrientes (BRADY, 1989), o que é benéfico para as plantas.

Em relação ao processo fenológico, os resultados indicaram que o período de florescimento ocorreu entre dezembro e abril no tratamento T4, período de florescimento normal da pitaya no Brasil (MARQUES et al., 2011). Entretanto, a propagação da pitaya realizada através da estaquia apresenta floração de um a dois anos após o plantio, de acordo com Andrade et al. (2007) e Gunasena et al. (2007).

Dessa maneira, pode-se afirmar que o crescimento dos cladódios foi diretamente influenciado pela presença de esterco bovino (Figura 6), permitindo sinalizar ao produtor uma maior rapidez no crescimento das matrizes, bem como no surgimento de flores e frutos em apenas oito meses após o plantio.

Grande parte dos trabalhos de adubação envolvendo espécies de pitaya destaca a importância da fertilização mineral, que apresenta a vantagem de poder ser absorvida rapidamente pelo sistema radicular; a pitaya, por apresentar sistema radicular superficial, absorve de forma mais rápida os nutrientes presentes na camada superficial do solo, quando disponíveis (LE BELLEC et al., 2006). Por este motivo, a adubação química precisa ser refeita periodicamente. Por outro lado, a adubação orgânica permite uma liberação contínua dos nutrientes, disponibilizando-os por mais tempo para a espécie, o que pode facilitar o crescimento das plantas. Aliado a este fator, as alterações físico-químicas do solo também influenciam, positivamente, no crescimento da espécie.

$\mathrm{Na}$ Califórnia, estudos apontam que estercos de origem animal têm gerado bons resultados no cultivo da pitaya, os quais substituem, completamente, a suplementação mineral (THOMSON, 2002), informações que confirmam os resultados obtidos por este trabalho.

\section{Conclusão}

A pitaya, quando em solos arenosos, cresce em menos tempo, quando a estes são adicionados materiais orgânicos, além de reduzir o período para a primeira floração e frutificação. Recomendando-se, para esses resultados, a utilização de $80 \%$ solo $+20 \%$ esterco bovino. 


\section{Referências}

ABREU, W. C. et al. Características físico-químicas e atividade antioxidante total de pitaias vermelha e branca. Rev. Inst. Adolfo Lutz, v.71, n.4, p.656-61, 2012.

ANDRADE, R.A. et al. Influência da fonte e do tempo de cura na propagação vegetativa da pitaya vermelha (Hylocereus undatus Haw.). Rev. Bras. Fruticul., v.29, n.1, p.183-186, 2007. doi: 10.1590/S0100-29452007000100039.

ANDREOLA, F. et al. A cobertura vegetal de inverno e a adubação orgânica e, ou, mineral influenciando a sucessão feijão/ milho. Rev. Bras. Ciênc. Solo, v.24, n.4, p.867-874, 2000. doi: 10.1590/S0100-06832000000400018.

BASTOS, D.C. et al. Propagação da pitaya "vermelha" por estaquia. Ciênc. Agrotecnol., v.30, n.6, p.1106-1109, 2006. doi:10.1590/S1413-70542006000600009.

BRADY, N.C. Natureza e propriedade dos solos. Rio de Janeiro: Freitas Bastos, 1989.

CANTO, A.R. El cultivo de pitahaya en Yucatán. Yucatán: Universidad Autónoma Chapingo, 1993.

CALVENTE, A. Filogenia molecular, evolução e sistemática de Rhipsalis (Cactaceae). São Paulo: Universidade de São Paulo, 2010.

CUNHA, A.M. et al. Efeito de diferentes substratos sobre o desenvolvimento de mudas de Acacia sp. Rev. Arvore, v.30, n.2, p.207-214, 2006. doi: 10.1590/S0100-67622006000200007.

DEMBITSKY, V.M. et al. The multiple nutrition properties of some exotic fruits: biological activity and active metabolites. Food Res. Int., v.44, n.7, p.1671-1701, 2011. doi: 10.1016/j. foodres.2011.03.003.

DONADIO, L.C. Pitaya. Rev. Bras. Fruticul., v.31, n.3, p.637929, 2009.

ESTELLANA, N.T. Dragon fruit production guide. Pinoy bisnes ideas: money making business ideas for entrepreneurs. 2011. Disponível em: <http://www.pinoybisnes.com/ agribusiness/ dragon-fruit-production>. Acesso em: 27 jun. 2020.

FREITAS, S.T.; MITCHAM, E.J. Quality of pitaya fruit (Hylocereus undatus) as influenced by storage temperature and packaging. Scie. Agricola, v.70, n.4, p.257-262, 2013. doi: 10.1590/S0103-90162013000400006.

GUNASENA, H.P.M et al. Dragon fruit (Hylocerus undatus (Haw.) Britton \& Rose). In: PUSHPAKUMARA, D.K.N.G. et al. Underutilized fruit trees in Sri Lanka. New Delhi: World Agroforestry Centre, 2007. p. 110-142.

HOFFMANN, I. et al. Farmers management strategies to maintain soil fertility in a remote area in northwest Nigerian. Agricul. Ecosystems \& Environment, Enschede, v.86, n.3, p.263275, 2001.

HOR, S.Y. et al. Safety assessment of methanol extract of red dragon fruit (Hylocereus polyrhizus): Acute and subchronic toxicity studies. Regulatory Toxicol. Pharmacol., v.63, n.1, p.106-114, 2012. doi: 10.1016/j.yrtph.2012.03.006.

HUNT, D.R et al. The New Cactus Lexicon. Devon: DH Books. 2006.

IBGE. Instituto Brasileiro de Geografia e Estatística. Resultados do Censo Agropecuário 2017. Disponível em: <https://censos. ibge.gov.br/agro/2017/>. Acesso em: 27 jun. 2020.

KELLEHER, B.P. et al. Advances in poultry litter disposal technology - a review. Bioresource Technol., v.83, p.27-36, 2002. doi: 10.1016/s0960-8524(01)00133-x.
KRAPOVICKAS, A. Las ilustraciones de la "Historia general y natural de las indias, islas y tierrafirme del mar océano" de Gonzalo Fernandez de Oviedo y Valdéz, Bonplandia, v.19, n.1, p.91-96, 2010.

LE BELLEC, F. et al. Pitahaya (Hylocereus spp.): a new fruit crop, a market with future. Fruits, v 61, n.4, p.237-250, 2006. doi: 10.1051/fruits:2006021.

MARQUES, V.B. et al. Fenologia reprodutiva de pitaia vermelha no município de Lavras, MG. Ciênc. Rural, v.41, n.6, p.984-987, 2011. doi: 10.1590/S0103-84782011005000071.

MINAMI, K.; PUCHALA, B. Produção de mudas de hortaliças de alta qualidade. Horticultura Bras., v. 18, p. 162-163, 2000.

MS RURAL. Adaptada ao clima e de manejo simples, produção de pitaya ganha espaço em MS. Disponível em <http://g1.globo. $\mathrm{com} / \mathrm{mato}$-grosso-do-sul/ms-rural/videos/v/adaptada-ao-climae-de-manejo-simples-producao-de-pitaia-ganha-espaco-emms/4975674/>. Acesso em 10 mar. 2020.

OLIVEIRA, A.N.P. et al. Yield of gherkin in response to doses of bovine manure. Horticul. Brasileira, v. 27, n. 1, p. 100-102, 2009. doi: 10.1590/S0102-05362009000100020.

ORTIZ-HERNÁNDEZ, Y. D.; CARRILLO-SALAZAR, J. A. Pitahaya (Hylocereus spp.): a short review. Comunicata Scientiae, v. 3 , n. 4 , p. $220-237$, 2012. doi: 10.14295/cs.v3i4.334.

ORTIZ-HERNÁNDEZ, Y. J. Pitahaya: Un Nuevo Cultivo para México. Colección de Textos Politécnicos. México: Limusa/ Noriega Editores, 1999.

PAUleTtI, V.; MOTTA, A.C.V. Fontes alternativas de nutrientes para adubação de pastagens. In: SIMPÓSIO SOBRE MANEJO DA PASTAGEM. FUNDAÇÃO DE ESTUDOS AGRÁRIOS "LUIZ DE QUEIROZ". PIRACICABA. Anais... Piracicaba: Fundação de Estudos Agrários "Luiz de Queiroz", 2004.

RIZZINI, C.T. Cactáceas: Os segredos da sobrevivência. Rev Ciênc. Hoje, v.5, n.30, p.30-37, 1987.

RODRÍGUEZ CANTO, A. Pitahayas: Estado mundial de su cultivo y comercialización. Maxcanú, Yucatán, México. Fundación Yucatán Produce, AC. Universidade Autonoma Chapingo, 2000.

RODRÍGUEZ CANTO, A. Las pitahayas em las artes plásticas, la historia y la literatura. Chapingo, Texcoco, México. Universidad Autónoma Chapingo, 2013.

ROGEZ, H. et al. Chemical composition of the pulp of three typical Amazonian fruits: araçá-boi (Eugenia stipitata), bacuri (Platonia insignis) and cupuaçu (Theobroma grandiflorum). Euro. Food Res. Technol., v.218, n.4, p.380-384, 2004. doi: 10.1007/s00217-003-0853-6.

SCHWARTZ, G. et al. Espécies arbóreas da sede da EMBRAPA Amazônia Oriental: Conservação ex situ e um novo espaço de educação Ambiental em Belém. Rev. Ciênc. Agrárias, v.1, p.181194, 2006.

SILVA, A.C.C. et al. Qualidade de frutos de pitaya em função da época de polinização, da fonte de pólen e da coloração da cobertura. Rev. Bras. Fruticul., v.33, n.4, p.1162-1168, 2011. doi: 10.1590/S0100-29452011000400014.

SIMPLÍCIO, A.A. et al. A caprino-ovinocultura de corte como alternativa para a geração de emprego e renda. Sobral: Embrapa Caprinos, 2004.

SOUTO, P. C. et al. Decomposição de estercos dispostos em diferentes profundidades em área degradada no semi-árido da Paraíba. Rev. Bras. Ciênc. Solo, v.29, n.1, p.125-130, 2005. 
THOMSON, P. Pitahaya (Hylocereus species): a promising new fruit crop for Southern California. Bonsall: Bonsall Publications, 2002.

WANITCHANG, J. et al. Maturity sorting index of dragon fruit: Hylocereus polyrhizus. J. Food Eng., v.100, n.3, p.409-416, 2010. doi: 10.1016/j.jfoodeng.2010.04.025.

$\mathrm{XU}$, L. et al. Structure characteristics of a water-soluble polysaccharide purified from dragon fruit (Hylocereus undatus) pulp. Carbohydrate Polymers, v.146, p.224-230, 2016. doi: 10.1016/j.carbpol.2016.03.060.

ZAPPI, D.C.; TAYLOR, N. Diversidade e endemismo das Cactaceae na Cadeia do Espinhaço. Megadiversidade, v. 4, n. 2, p. 111-116, 2008.

ZANIN, T. 6 benefícios da Pitaya, principais tipos e como comer, 2007. Disponível em: https://www.google.com.br/ search?q=pitaya. Acesso em: 10 mar. 2020. 